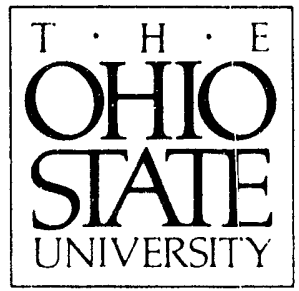

\title{
Installation and Evaluation of a Nuclear Power Plant Operator Advisor Based On Artificial Intelligence Technology
}

Brian K. Hajek and Don W. Miller

Nuclear Engineering Program

Department of Energy

Idaho Falls, Idaho 83401-1562

Contract No. DE-FG07-88ER12819

Final Report

RF Project No. $767097 / 721501$

February 1993

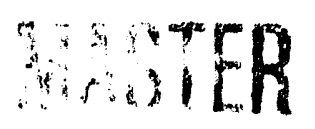




\title{
T A B L E O F C O N T E N T S
}

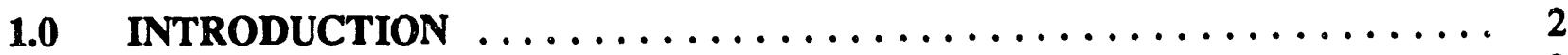

1.1 Goals and Objectives of the Research $\ldots \ldots \ldots \ldots \ldots \ldots \ldots \ldots \ldots, 2$

1.2 Completion of Software Conversion and Development $\ldots \ldots \ldots \ldots \ldots \ldots 3$

1.3 Continuation of Knowledge Expansion $\ldots \ldots \ldots \ldots \ldots \ldots \ldots \ldots, \ldots \ldots$

1.4 Development of User Interfaces $\ldots \ldots \ldots \ldots \ldots \ldots \ldots \ldots \ldots \ldots \ldots, 5$

1.5 Continuation of the V\&V Program .................... 5

1.6 On-Line Testing with Power Plant Operators $\ldots \ldots \ldots \ldots \ldots \ldots \ldots \ldots 6$

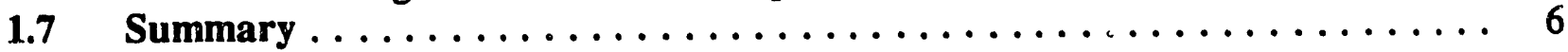

2.0 Recommendations for Future Research $\ldots \ldots \ldots \ldots \ldots \ldots \ldots \ldots$

$2.1 \quad$ Knowledge Representation $\ldots \ldots \ldots \ldots \ldots \ldots \ldots \ldots \ldots \ldots \ldots \ldots \ldots$

2.2 Man-Machine Interfaces $\ldots \ldots \ldots \ldots \ldots \ldots \ldots \ldots \ldots \ldots \ldots \ldots, 8 \ldots \ldots, \ldots \ldots$

2.3 Procedure Synthesis ............................. 10

2.4 Verification \& Validation $\ldots \ldots \ldots \ldots \ldots \ldots \ldots \ldots \ldots \ldots \ldots$

3.0 CONTRIBUTIONS TO GRADUATE EDUCATION ............. 12

3.1 Students Having Worked on the Operator Advisor Project $\ldots \ldots \ldots \ldots \ldots 12$

3.2 Research Completed During Prior Years ................... 12

3.3 Research Completed During the Third Project Year $\ldots \ldots \ldots \ldots \ldots \ldots 13$

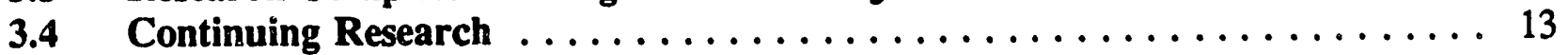

4.0 REFERENCES $\ldots \ldots \ldots \ldots \ldots \ldots \ldots \ldots \ldots \ldots \ldots \ldots \ldots \ldots \ldots \ldots$

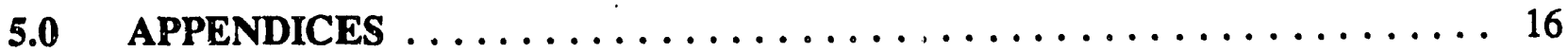

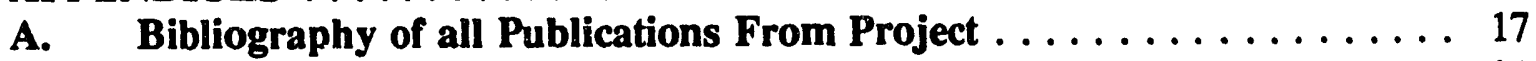

B. Publications From Third Project Year Efforts $\ldots \ldots \ldots \ldots \ldots \ldots 21$

\section{DISCLAIMER}

\begin{abstract}
This report was prepared as an account of work sponsored by an agency of the United States Government. Neither the United States Government nor any agency thereof, nor any of their employees, makes any warranty, express or implied, or assumes any legal liability or responsibility for the accuracy, completeness, or usefulness of any information, apparatus, product, or process disclosed, or represents that its use would not infringe privately owned rights. Reference herein to any specific commercial product, process, or service by trade name, trademark, manufacturer, or otherwise does not necessarily constitute or imply its endorsement, recommendation, or favoring by the United States Government or any agency thereof. The views and opinions of authors expressed herein do not necessarily state or reflect those of the United States Government or any agency thereof.
\end{abstract}




\subsection{INTRODUCTION}

The Artificial Intelligence Group in the Nuclear Engineering Program has designed and built an Operator Advisor (OA), an AI system to monitor nuclear power plant parameters, detect component and system malfunctions, diagnose their causes, and provide the plant operators with the correct procedures for mitigating the consequences of the malfunctions. It then monitors performance of the procedures, and provides backup steps when specific operator actions fail. The OA has been implemented on Sun 4 workstations in Common Lisp, and has been interfaced to run in real time on the Perry Nuclear Power Plant fullfunction simulator in the plant training department.

The eventual goal for a fully functioning Operator Advisor would be to have reactor operators receive direction for all plant operations. Such a goal requires considerable testing of the system within limited malfunction boundaries, an extensive Verification \& Validation (V\&V) effort, a large knowledge base development effort, and development of tools as part of the system to automate its maintenance. Clearly, these efforts are beyond the scope of the feasibility effort expended during this project period. However, as a result of this project, we have an AI based platform upon which a complete system can be built.

In Chapter 1, we summarize the activities completed during the third year of the project in support of the goals established for the project.

In Chapter 2, we discuss the direction that future research should take to reach the eventual goal of implementing the Operator Advisor on an actual plant.

In Chapter 3, we discuss the contributions this project has made to graduate education, and how it has contributed to other DOE research as well as nuclear industry initiatives.

The Attachments include copies of papers that resulted from this research that have been published during and following the third project year.

\subsection{Goals and Objectives of the Research}

The revised goals for the third year of this project were to:

1. Incorporate improvements made possible through theoretical extensions resulting from previous NSF sponsored research, especially related to the effective use of information in dynamic data, and improved AI methods for using dynamic data.

2. Complete all software conversion and development to enable total implementation of the Operator Advisor on Sun workstations.

3. Select additional testing scenarios, and add knowledge for testing the scenarios with actual plant operators. 
4. Complete divelopment of the three required man-machine interfaces: (1) Developmert Interface, (2) Maintenance Interface, and (3) User Interface. Obtain input from plant operators for the User Interface.

5. Continue the Validation phase of the V\&V Program by evaiuating the response of the Perry Nuclear Power Plant and plant operators with and without the Operator Advisor.

6. Continue to expand the Operator Advisor to handle additional systems and malfunctions.

7. Modify and improve the Operator Advisor and man-machine interface in accordance with findirigs from the $V \& V$ process, operator evaluations, and response evaluations from Goals 4 and 5.

Though all these goals have not been met, considerable progress has been made in creating a platform upon which elements of a fully functioning Operator Advisor can be built. The following sections detail the work completed during the third year of this project, their relationship to the overall effort, and how each activity supported the project goals.

The following sections reference papers written and presented in support of this research. They also mention when the work contributed to thesis or dissertation completion. Specific discussion of the thesis and dissertation efforts is saved for Chapter 3.

\subsection{Completion of Snftware Conversion and Development}

Conversion of the Plant Status Monitoring System (PSMS) and Diagnostic and Sensor Validicion System (DVS) to Common Lisp for running on the Sun workstations was completed, including upgrades to the latest versions of the Sun operating system and Common Lisp.

The Database, previously re-written using the Informix Database Management System, now runs in a hybrid environment to use the data archiving capabilities of Informix and the speed capabilities of the pure Common Lisp environment.

The Dynamic Procedure Management System (DPMS) had been converted to the ENVOS Medley environment, but ran too slowly for use in the Sun operating system. DPMS continued to be available for use in the Koto environment on the previously used Xerox workstations with an Ethernet connection to the Sun workstation. However, the remaining Xerox workstations are unreliable, and so the current version of DPMS effectively is not available for use with the OA. Rather than beginning a straight forward conversion to Common Lisp for use on the Sun workstations, we are rethinking the structure of DPMS (1). It is the subject of current $\mathrm{Ph}$. D. dissertation research, and should be available again in the future. 
This task supported Goal Number 2. The enhancements being made to DPMS incorporate theoretical extensicns that resulted from earlier NSF supported research, and thus support Goal Number 1.

\subsection{Continuation of Knowledge Expansion}

Knowledge continued to be added to the Operator Advisor to support student research using

(1) a systems approach (which is very systematic),

(2) a scenario support approach (which emphasizes integrated plant performance), and

(3) a model development approach.

These efforts included knowledge related to the Residual Heat Removal System, the APRM System, and the Reactor Recirculation System.

To support the continuing development of DPMS, testing scenarios were and continue to be developed. Knowledge to support these scenarios is being identified for addition to the OA.

One effort to enhance the diagnostic capabilities of the OA using plant models resulted in a dissertation involving the use of qualitative physics models and constraint propagation (2).

Another effort, not yet finished, involves the use of modeling using a hierarchical collection of quantitative models together with a structured residual approach $(3,4)$. This involves a structured decomposition rather than the malfunction based decomposition used before. Besides testing another diagnostic tool within the overall structure of the OA, this research also will result in the ability to test response hypotheses in the Dynamic Procedure Management System prior to actually implementing a procedure step.

Knowledge related to the RHR System has been added to the Xerox version of the Operator Advisor. The research related to this knowledge addition answered questions on establishing operating modes of both the plant and the RHR System without requesting manual input of data from the plant operators. A key aspect of this research developed a procedure for implementing a functional decomposition methodology for knowledge acquisition and addition to the $\mathrm{OA}(5)$.

As knowledge is being added, the process for maintaining the knowledge has evolved through the development of a window-based interface. This is expected to continue to be a fluid process as the Maintenance Interface development progresses. Thus, this task supports the man-machine interface development goal as well.

This task supported Goals 3, 4, and 6. 


\subsection{Development of User Interfaces}

Work progressed on the three interfaces identified in Goal 4. Since the OA continues to be in the development phase, the emphasis was placed on the development interface. However, the hierarchical structure display that has been developed lends itself to use by all three user types - the developer, the system maintenance personnel, and the reactor operator as the end user. The hierarchical displays have not been optimized for providing information to the end user, nor have they been tested with end users.

Design of the man-machine interface was facilitated by the capabilities of the X11 window system we implemented on the Sun workstations. The text based display was enhanced with development of a hierarchy tree structure display that now provides a development and user environment similar to the one we had in the Xerox environment at the beginning of the project prior to converting to the Sun workstations.

The hierarchical structure allows the developer to structure a diagnostic tree for which the pruning process is clearly displayed. It also allows a person who maintains the system to make changes to the logic structure and have them immediately displayed. Finally, the end user can easily follow the diagnostic reasoning that leads to the conclusions because a color enhanced indication of the conclusion has been implemented.

The current interface also allows the reactor operator to be presented with procedural steps, and will enable the reactor operator to query the Operator Advisor concerning its diagnosis of off-normal conditions.

This task supports Goals 4 and 5.

\subsection{Continuation of the V\&V Program}

A formal V\&V Program was implemented with the completion of a specification document for the Operator Advisor, and various tests including off-line real-time dynamic testing $(6,7)$. These methods have been refined as part of another DOE project $(8)$.

As knowledge is entered, the OA will be tested on the Perry Simulator. However, no formal procedures have been developed for these tests as of this time. This testing will contribute to the verification side of the $\mathrm{V} \& \mathrm{~V}$ process.

Validation testing must be preceded by additional work on the user interface. It also requires that significantly more knowledge be added to the OA. Finally, the complete OA cannot be tested with plant operators until the Dynamic Procedure Management System (DPMS) is implemented on the Sun workstations.

These efforts support Goal 5. 


\subsection{On-Line Testing with Power Plant Operators}

On-line testing was planned for the third project year. However, little progress was made on this goal because of the extensive programming required to complete the conversion to the Sun workstations, and due to Perry replacing their simulator. This latter activity occurred during the ninth month of the third project year, and required that a completely new Simulator/OA interface be designed and installed. This interface was designed, has been tested in a simulator environment similar to the Perry simulator, but is not yet installed on the Perry simulator.

The Sun workstation has been connected to the Perry Simulator, protocols for data transmission have been written and tested, but conversion of data has not been completed. References for all simulator data were changed in the new simulator configuration, and an extensive effort is required to convert to this new system. Work is continuing to support current research.

This remains a goal of the research, but must be delayed for future work. Thus progress on Goal 7 was not made during the final project year.

\subsection{Summary}

Significant progress has been made on the development of a knowledge-based system to assist power plant operators with malfunction identification, diagnostic assistance, and procedure implementation. A platform is now available on which additional knowledge may be added, user interface research may be pursued, and operator interaction may be studied.

The Operator Advisor System has been interfaced to run in real time on the Perry Nuclear Power Plant Training Simulator. A serial interface was demonstrated to work on the old Perry Simulator with a data transfer rate of over 400 points per second. The interface to the new simulator uses an Ethernet connection for higher data transfer rates. Installation of this interface has been completed, testing in a similar environment has been completed, bat testing of the OA in this new environment has not yet been performed.

Plans for future work include the addition of plant knowledge, improvements in the user interfaces, and redesign of the Dynamic Procedure Management System. This work is discussed in Chapter 2.

During the final project year, one M.Sc. thesis was completed, and one Ph.D. dissertation was completed. Additional work was done which will lead to another M.Sc. degree and two Ph.D. degrees. This brings the total number of degrees emanating from this project through thesis or dissertation research to six at the Masters level and four at the Doctorate level. These contributions to graduate education are discussed in Chapter 3. 
Future research should continue to complete the efforts on the goals originally established for the three years of this project. In the near term, primary emphasis will continue to be placed on adding diagnostic knowledge to the $O A$ and in investigating efficient knowledge representations and diagnostic techniques. This effort is in support of development work on the Dynamic Procedure Management System which requires diagnostic knowledge to assist with recovery procedure implementation. Also, a Ph.D. dissertation using a hierarchical collection of quantitative models together with a structured residual approach will be completed during 1993. This work will support the predictive requirements for implementing DPMS. Finally, further development of the user interfaces is necessary to improve user interaction with the system. Important to this effort is research into the human-machine interaction with making the machine a true extension of the operator rather than an independent tool.

Any additional programming must also occur within the framework of the V\&V program for the Operator Advisor. Testing and documentation must reflect the importance of this system to the safe operation of the power plant as well as the safe recovery from plant transients.

\subsection{Knowledge Representation}

Expansion of the knowledge in the OA is continuing in the framework of the CSRL program structure. This structure has recently been implemented in the $\mathrm{C}++$ language on the Sun workstations. This implementation enables the OA to run significantly faster than it had run in Lisp.

Our research on this project has found that knowledge is easy to represent in CSRL for diagnostics on single plant systems. However, when systems interact, and when temporal knowledge needs to be considered, CSRL has considerable shortcomings. Thus, the implementation in $\mathrm{C}++$ also enables us to easily interface with other $\mathrm{C}++$ programs, and to easily investigate various modeling strategies.

Future research will stress the comparison and testing of several knowledge representations to test their relative effectiveness for this application. We need to use the knowledge in at least three applications in this study: monitoring, diagnosis, and procedure management. So it is imperative that all selected techniques allow for a single set of knowledge that can be accessed for all applications. This is the same as the human mind functions. We grab what we need only when it's needed, and massage it for different uses as appropriate.

We are currently looking at functional representations, malfunction hypothesis representations, mixed representations, and several modeling methods including the use of structured residuals in a malfunction hierarchy. 


\subsection{Man-Machine Interfaces}

The OA requires three interfaces. These are the Developer's Interface, the Maintenance Interface, and the Plant Operator-Computer Interface. We currently have only one that is serving all three purposes. This is sufficient at the present since operators aren't being used yet in the on-line performance evaluations. However, major emphasis must be placed in this area in the near future.

The following paragraphs briefly describe the three interfaces and their history on the OA Development Project.

\section{Developer's Interface}

The Xerox Interlisp-D development environment provided a number of convenient graphical tools to aid in the development of expert systems. These enabled hierarchies to be created, and then to be pruned or grafted as understanding of the knowledge structure developed. Such facilities were not available in the new environment we are working in on the Sun workstations.

We have implemented several development aids in the X11 window system. However, we don't have the "browser" facilities that were so useful in the Xerox environment. We anticipate these will be developed by others during the next year or two. In the interim, we require several graphical aids to view our knowledge structures.

The purpose of this task is to develop relatively minimal graphical aids to assist us in the development and demonstration process.

\section{Maintenance Interface}

Two maintenance tasks are of concern. The first is that of adding knowledge and data to the Operator Advisor. The second is maintaining this information.

Data will be maintained in the database in the form of objects. A user-friendly facility for adding and modifying this data needs to be specified and designed. Various screen formats have already been designed for adding data to the database.

Knowledge includes the rules and objects in the three expert systems that analyze plant conditions and provide guidance to the reactor operators. The interfaces for adding this knowledge will be similar to that for entering data. In addition, it should also include automated rule generators that will force the syntax to remain consisient and understandable by all three expert systems. 


\section{Plant Operator-Computer Interface}

This interface allows the end user, the plant operator, to receive guidance from the Operator Advisor. It also should allow the plant operator to query the OA when he wants to know the basis of the reasoning provided by the system; the contents of a procedure not currently displayed; the contents of different procedure steps of the current procedure, including both those already executed as well as those still to be executed; the possible effects of contemplated actions; values of specific data points not otherwise provided; and trends of important plant parameters that might affect decision making.

We continue to work with the Perry Nuclear Power Plant Training Department staff to obtain recommendations for the plant operator-computer interface. We also expect to continue to employ graduate students on this project who have Navy or power plant operating experience.

This task involves several interim steps to assure an effective and viable interface, and there are several interim objectives that should be accomplished before the OA is introduced into the Control Room environment for operator use. These include:

1. Research into Human Intelligent Computer Interaction to identify the conditions under which humans are both least and most likely to demand assistance from an intelligent system, and the conditions under which these demands occur. This research will provide guidelines for development of the contents of realistic simulator scenarios and the plant operator-computer interface.

2. Realistic simulator scenarios should be developed and validated. The scenarios will be similar to currently used training and testing scenarios. They will be run for several shift crews as part of the validation process. After being validated, the knowledge needed to support them will be programmed into the $O A$, and an additional verification and validation process will be completed for the expert system.

3. A prototype plant operator-computer interface should then be completed. The $O A$ can then be moved from the simulator computer room, where initial work is being completed, onto the simulator floor (requiring a longer cable) for use by the plant operators in responding to the scenarios. Their performance will be measured in relation to their performance without the OA to determine a measure of its efrectiveness in assisting them with their tasks. 
4. The OA plant operator-computer interface will be modified based on the findings of the testing (validation) program to improve its effectiveness.

A result of this research task may be the development of guidelines to assist in the development of future intelligent computer systems for aiding operators in plant operations.

\subsection{Procedure Synthesis}

The procedure synthesis concept can be stated as: At any given time, only the current procedure step can be known. Subsequent steps need to be synthesized in response to the change requirement. This was first proposed for the nuclear power plant environment using AI techniques by D. D. Sharma in 1986 (9). Specifications for a knowledge-based system for successfully implementing procedure synthesis must include monitoring, diagnostic, and consequence prediction components. (The first two have been implemented for the OA in the Sun workstation environment, and the third needs yet to be developed, although it was previously implemented in a lesser version in the Xerox workstation environment.) In addition, the knowledge-based system should have access to a library of procedural steps indexed by goals so that a procedure can be constructed by selecting and collecting the appropriate steps in runtime.

The purpose of the monitoring system is to monitor plant data and the success of actions executed. The purpose of the diagnostic system is to identify and isolate actions that can be executed in spite of system malfunctions, and to determine the current plant state. The consequence predictor must determine the expected resultant plant state before procedure steps are actually executed. That is, under current plant conditions, if a given action is taken, what will its effect be on achieving the goal of placing the plant in a safer state.

An issue of concern is the level of fault diagnosis required before procedure synthesis can be started. Another concern is what should happen if it was not possible to isolate the faults. One way of handling such situations is to use a system that performs temporal data analysis whose results can be used by the consequence predictor for the selection of appropriate but not necessarily final actions.

After the current plant state is determined, consequence prediction can be started. The objective of consequence prediction is to predict and determine the effects of actions on the plant prior to actually implementing the action. This requires continuous simulation of the plant as faults progress and actions (auto/manual) are executed. This raises the additional issue of the quality and speed of the simulation.

Time constraints include diagnosis time, action execution time, and plant and action simulation time, during the implementation of procedure synthesis. The plant state and the severity of an accident will affect the selection of actions and procedural steps. Therefore, based on the severity of an accident and the estimated time needed to perform 
diagnosis, simulation, and action execution, the knowledge-based system should be able to select the most appropriate path for action implementation.

Another issue is what happens if the knowledge-based s s ystem encounters conflicting goals. The knowledge-based system should have the abilit:' to prioritize and select the most important goals to be pursued.

This research is the topic of dissertation research to be completed over the next two or three years.

\subsection{Verification \& Validation}

In addition to the verification tests being performed as knowledge is added, we also must implement procedures for exhaustive testing of the rules and objects, and inference testing.

These efforts, however, support only the Verification side of the V\&V equation.

Validation testing may begin after additional knowledge is added and after an effective user interface is implemented. Our current approach to adding knowledge, as noted above, involves both systems and scenario based methods. When sufficient knowledge is available to test several scenarios with operators, then initial validation testing can begin. It would be preferable to wait until significant user interface work has been completed. However, we believe this would delay validation longer than desired.

Initial validation testing will compare reactor operators' responses to plant off-normal conditions with and without the Operator Advisor. 


\subsection{CONTRIBUTIONS TO GRADUATE EDUCATION}

\subsection{Students Having Worked on the Operator Advisor Project}

This project has provided research support for a total of 13 graduate students from three departments on The Ohio State University campus: Nuclear Engineering, Chemical Engineering, and Computer \& Information Science (CIS).

Eight students have completed degree work, one has left without completing his degree, three have taken jobs in the nuclear industry and are completing their research work while in these jobs (one MS and two $\mathrm{PhD}$ ), and two remain at OSU and expect to complete their degree work in the near future (one MS and one PhD). One student has been cousted twice since he completed an MS degree with a thesis and is now working in the nuclear industry having completed most requirements for his $\mathrm{PhD}$ except for his dissertation research.

Thus, 12 students supported by this research will have graduated from OSU programs. Of these 12 students, eight have or will have used the Operator Advisor as the central topic of their graduate research. The other four (two in CIS, one in Chemical Engineering, and one, in Nuclear Engineering) will have completed their research work in the broader field of Artificial Intelligence research and/or applications, and used their experience in working on this project to contribute to their research.

The remaining part of this section will detail only the research directly related to the Operator Advisor project.

\subsection{Research Completed During Prior Years}

\section{Research Completed During the First Year}

Two students completed their research during the first year of the project. This work was actually begun prior to the start of the current project, and created the foundation upon which the Operator Advisor was built.

Rajiv Bhatnagar completed his Ph.D. Dissertation which addressed the integration of diagnosis and procedure management modules. He was responsible for conceptualization and implementation of the intelligent data base and the Plant Status Monitoring System (PSMS). Mr. Bhatnagar's research also addressed temporal issues and integration of qualitative and quantitative reasoning.

Tom Jakubowski developed a method for dynamic testing of the OA using scenario data from the Perry Nuclear Power Plant simulator. This became an important component of the verification program for the $\mathrm{OA}$. This research and the testing through use of several Perry Plant scenarios served as the basis for Mr. Jakubowski's M.Sc. Thesis completed. 


\section{Research Completed During the Second Year}

Loay Khartabil added knowledge related to the RHR System to the Operator Advisor for his M.Sc. thesis research. As part of this research, he answered questions on establishing operating modes of both the plant and the RHR System without reque:ting manual input of data. A key aspect of this research was to develop a procedure for implementing a functional decomposition methodology for knowledge acquisition in order to facilitate data entry. He completed his thesis research in Summer Quarter, 1990.

Mr. Khartabil continued with the OA project after completion of this work to continue his education in pursuit of a Ph. D. His research concentrated on the Dynamic Procedure Management System, with an emphasis on implementing a full procedure synthesis methodology. This is continuing work that will require several years to complete.

\subsection{Research Completed During the Third Project Year}

While the OA continued to grow during the third year, no thesis or dissertation work was completed. However, third year efforts led to the completion of two theses in early 1992.

Prabal Acharyya investigated the application of functional representation for representing how device ínnctions arise from causal processes in which subcomponents play multiple roles. The objective was to investigate and develop alternative knowledge representation schemes for the OA to provide efficient diagnoses of malfunctions. His M. Sc. thesis work was completed in Summer, 1992.

Jae-Joo Ha investigate the application of models using constraint networks to diagnose faults in the hydraulic power units of the flow control valves in the reactor recirculation system. The structure and behavior model was represented symbolically in algebraic equations. A component library was used to increase the efficiency of both model construction and use. Any behavior that deviates from expected behavior is considered a fault to be diagnosed. Assumptions that describe the normal behavior of the system are built into the system and are used to identify a specific malfunctioning component. Dr. Ha completed his research in Spring, 1992.

Both these efforts have contributed to a necessary extension of the OA diagnostic methodologies to use various system models. Models will enable us to predict future behavior so that procedures can be tested prior to their implementation, a necessary function for implementing a procedure synthesis system.

\subsection{Continuing Research}

Research begun during the second and third years of the OA project is continuing. Also, several research areas previously identified remain for further analysis. Currently continuing efforts include the organization and addition of knowledge to support the diagnostic and procedure management modules, development of modeling techniques 
using a hierarchical organization and structured residuals, improvements in the C++ implementation of the software, and improvements in the currently available user interfaces. Also, to support each of these efforts, the software to transfer data from the new first principles Perry simulator is still being written.

It was noted by Chuck Hardy that when a fault occurred in one of the two loops of the Reactor Recirculation System the OA could not distinguish which loop the fault was in or what the fault was under several conditions. This was because changes in forced circulation in one loop caused the opposite changes in the flow of the other loop. Mr. Hardy hypothesized that a model-based approach might eliminate this problem. Thus, he devised a method to utilize hierarchical classification, with which we have considerable experience in the OA project, with component and function models as a decoupling technique to isolate faults in closely interacting systems. His research is essentially complete, and he is currently writing his dissertation. He should receive his Ph.D. before the end of 1993.

Mr. Wes Hines, who worked on the OA project during its first year before transferring to a project to develop diagnostic methods for the Savannah River K Reactor, will continue Mr. Hardy's research in pursuit of his Ph.D.

Satoru Kiyohashi began working with the OA development group half way through the third year. His research for his M.Sc. degree involves knowledge implementation for several systems in support of integrated malfunction scenarios that will be used for further work with procedure synthesis. Thus, he has developed scenarios involving several plant systems and that extend require about one hour to fully develop on the simulator. The malfunctions that occur may or may not require operator action. Any action required will closely follow the requirements of plant operating procedures. He is in the process of identifying the knowledge required for diagnosing multiple problems in these systems and entering that knowledge in the OA. His thesis is scheduled for completion during Spring, 1993.

All the work on fault diagnosis will eventually support a sophisticated procedure management system. We expect the heart of this system to be a procedure synthesis methodology. Development of the initial implementation of this system is the subject of research leading to a Ph.D. dissertation for Loay Khartabil. This work is continuing without funding at the present time. Mr. Khartabil has taken a job in the nuclear industry and is continuing his dissertation research from off campus.

Another area requiring major future effort will be development of the plant operatorcomputer interface. No student has been identified to pursue this area at this time. 


\subsection{REFERENCES}

1. B. K. Hajek, L. F. Khartabil, and D. W. Miller. "Issues Involved in a Knowledge-Based Approach to Procedure Synthesis," Transactions of the ANS Winter Meeting, Chicago, II, November, 1992.

2. Ha, J., B. K. Hajek, and D. W. Miller. "Model Based On-Line Diagnosis of Plant Malfunctions Using Constraint Propagation," Proceedings of AI91, Frontiers in Innovative Computing for the Nuclear Industry, Jackson Lake, WY, September, 1991.

3. Hardy, C. R., D. W. Miller, and B. K. Hajek. "A Model-Based Approach to Malfunction Isolation in Interacting Systems," Proceedings of the Eighth Power Plant Dynamics, Control \& Testing Symposium, Knoxville, Tennessee, May, 1992.

4. Hardy, C. R., D. W. Miller, B. K. Hajek. "Structured Residual Technique for Malfunction Isolation in Interacting Systems," Transactions of the ANS Winter Meeting, Chicago, IL, November, 1992.

5. Khartabil, L. F., B. K. Hajek, and D. W. Miller. "An Expert System for Monitoring, Functionally Diagnosing, and Managing Operations for a Multiple Mode Nuclear Plant System," Proceedings of Al91, Frontiers in Innovative Computing for the Nuclear Industry, Jackson Lake, WY, September, 1991.

6. B. K. Hajek, C. R. Hardy, D. W. Miller, and R. Bhatnagar. "A V \& V Program for a Real Time Operator Advisor Expert System," Proceedings of the Expert Systems Applications for the Electric Power Industry Conference, sponsored by the Electric Power Research Institute, Orlando, Florida, June 5 - 8, 1989.

7. B. K. Hajek, T. Jakubowski, D. W. Miller, and S. Haggerty. "An Off-Line Time Dependent V\&V Testing Methodology For a Real Time Operator Advisor Expert System," Proceedings of the ANS Topical Meeting on Advances in Human Factors Research on Man-Computer Interactions:Nuclear and Beyond, Nashville, Tennessee, June, 1990. (Invited) (Complete paper published) (Peer evaluation of paper performed prior to publication)

8. J. W. Hines, B. K. Hajek, and M. A. Haas. "A Standardized Approach to Verification and Validation to Assist in Expert System Development," Proceedings of the EPRI Workshop on Expert System Applications For The Electric Power Industry, Boston, MA, September, 1991.

9. Sharma, D. D., "A knowledge Based Framework for Procedure Synthesis and its Application to the Emergency Response in a Nuclear Power Plant." Ph.D. dissertation, The Ohio State University, 1986. 


\subsection{APPENDICES}

A. Bibliography of all Publications From Project

B. Publications From Third Project Year Efforts 
Appendix A

Blbliography of All Publications from Project 


\section{Bibliography of all Publications From Project}

1. Sharma, D. D., Miller, D. W., and Chandrasekaran, B., "Design of an Artificial Intelligence System for Safety Function Maintenance," Transactions of the American Nuclear Society, Vol. 50, pp. 294 - 297, 1985.

2. D.D. Sharma, D.W. Miller, B.K. Hajek, and B. Chandrasekaran, "Intelligent Process Control Operator Aid - An Artificial Intelligence Approach," in Proceedings of the Sixth Power Plant Dynamics, Control and Testing Symposium, April, 1986.

3. Hashemi, S., Hajek, B. K., Miller, D. W., Chandrasekaran, B., Punch III, W. F., "An Expert System for Sensor Data Validation and Malfunction Detection." presented and published in the Proceedings of the ANS Conference on Artificial Intelligence and other Innovative Computer Applications in the Nuclear Industry, Snowbird, Utah, 1987.

4. Bhatnagar, R., Gandikota, Mi. S., Davis, J. F., Hajek, B. K., Miller, D. W., and Stasenko, J. E., "An Intelligent Database for Process Plant Expert Systems," presented and published in the Proceedings of the ISA 88 International Conference and Exhibit, Houston, TX, October, 1988.

5. "A Modular Real-Time Operator Advisor Expert System for Installation on a Full Function Nuclear Power Plant Simulator," by B. K. Hajek, D. W. Miller, and R. Bhatnagar. Proceedings of the Seventh Power Plant Dynamics, Control, and Testing Symposium, Knoxville, Tennessee, May, 1989 (Invited) (Complete Paper Published).

6. "The Knowledge-Based Framework for a Nuclear Power Plant Operator Advisor," by D. W. Miller and B. K. Hajek. Proceedings of the American Nuclear Society Annual Meeting, Atlanta, GA, June, 1989.

7. B. K. Hajek, C. R. Hardy, D. W. Miller, and R. Bhatnagar. "A V \& V Program for a Real Time Operator Advisor Expert System," Proceedings of the Expert Systems Applications for the Electric Power Industry Conference, sponsored by the Electric Power Research Institute, Orlando, Florida, June 5 - 8, 1989.

8. Hardy, C. R., P. K. Acharyya, B. K. Hajek, and D. W. Miller, "Intelligent Querying of a Relational Database," Proceedings of the EPRI Conference on Advanced Computer Technology for the Power Industry, Scottsdale, Arizona, October, 1989. (Complete paper published)

9. T. Jakubowski, B. K. Hajek, D. W. Miller, and R. Bhatnagar. "Transient Simulation for a Real-Time Operator Advisor Expert System," Proceedings of the Specialist's Meeting on Artificial Intelligence in Nuclear Power Plants, Helsinki, Finland, October 10 - 12, 1989. (Presented by B. K. Hajek) 


\section{Bibliography of all Publications From Project (Continued)}

10. Bhatnagar, R., D. W. Miller, B. K. Hajek, and J. E. Stasenko, "An Integrated Operator Advisor System for Plant Monitoring, Procedure Management and Diagnosis," . Nuclear Technology, March, 1990.

11. B. K. Hajek, T. Jakubowski, D. W. Miller, and S. Haggerty. "An Off-Line Time Dependent V\&V Testing Methodology For a Real Time Operator Advisor Expert System," Proceedings of the ANS Topical Meeting on Advances in Human Factors Research on Man-Computer Interactions:Nuclear and Beyond, Nashville, Tennessee, June, 1990. (Invited) (Complete paper published) (Peer evaluation of paper performed prior to publication)

12. Bhatnagar, R., D. W. Miller, B. K. Hajek, and B. Chandrasekaran, "DPRL: A Language for Representation of Operation and Safety Maintenance Procedures of Nuclear Power Plants," Proceedings of the Third International Conference on Industrial and Engineering Applications of Artificial Intelligence and Expert Systems, Charleston, South Carolina, July, 1990. (Complete paper published)

13. J. W. Hines, B. K. Hajek, and M. A. Haas. "A Standardized Approach to Verification and Validation to Assist in Expert System Development," Proceedings of the EPRI Workshop on Expert System Applications For The Electric Power Industry, Boston, MA, September, 1991.

14. C. R. Hardy, J. Ha, B. K. Hajek, and D. W. Miller. "A Real-Time Expert System for the Detection and Diagnosis of Abnormal Conditions in Nuclear Power Plants," Proceedings of AI91, Frontiers in Innovative Computing for the Nuclear Industry, Jackson Lake, WY, September, 1991.

15. Ha, J., B. K. Hajek, and D. W. Miller. "Model Based On-Line Diagnosis of Plant Malfunctions Using Constraint Propagation," Proceedings of AI91, Frontiers in Innovative Computing for the Nuclear Industry, Jackson Lake, WY, September, 1991.

16. Khartabil, L. F., B. K. Hajek, and D. W. Miller. "An Expert System for Monitoring, Functionally Diagnosing, and Managing Operations for a Multiple Mode Nuclear Plant System," Proceedings of AI91, Frontiers in Innovative Computing for the Nuclear Industry, Jackson Lake, WY, September, 1991.

17. Hardy, C. R., D. W. Miller, and B. K. Hajek. "A Model-Based Approach to Malfunction Isolation in Interacting Systems," Proceedings of the Eighth Power Plant Dynamics, Control \& Testing Symposium, Knoxville, Tennessee, May, 1992.

18. Hardy, C. R., D. W. Miller, B. K. Hajek. "Structured Residual Technique for Malfunction Isolation in Interacting Systems," Transactions of the ANS Winter Meeting, Chicago, IL, November, 1992. 


\section{Bibliography of all Publications From Project (Continued)}

19. B. K. Hajek, L. F. Khartabil, and D. W. Miller. "Issues Involved in a Knowledge-Based Approach to Procedure Synthesis," Transactions of the ANS Winter Meeting, Chicago, IL, November, 1992. 
Appendix B

Publications from Third Project Year Efforts 
The following publications are included in this Appendix.

1. "Implementation of a Real Time Expert System for the Diagnosis of Component Failures in a Nuclear Power Plant," by C. R. Hardy, J. Ha, B. K. Hajek, and D. W. Miller. Proceedings of Applications of Expert Systems, 1991 AIChE Spring National Meeting, Houston, TX, April, 1991 (Invited) (Complete Paper Published).

2. "A Real-Time Expert System for the Detection and Diagnosis of Abnormal Conditions in Nuclear Power Plants," by C. R. Hardy, J. Ha, B. K. Hajek, and D. W. Miller. AI91, Frontiers in Innovative Computing for the Nuclear Industry, Jackson Lake, WY, September, 1991.

3. "Model Based On-Line Diagnosis of Plant Malfunctions Using Constraint Propagation," by J. Ha, B. K. Hajek, and D. W. Miller. AI91, Frontiers in Innovative Computing for the Nuclear Industry, Jackson Lake, WY, September, 1991.

4. "An Expert System for Monitoring, Functionally Diagnosing, and Managing Operations for a Multiple Mode Nuclear Plant System," by L. F. Khartabil, B. K. Hajek, and D. W. Miller. AI91, Frontiers in Innovative Computing for the Nuclear Industry, Jackson Lake, WY, September, 1991.

5. "A Model-Based Approach to Malfunction Isolation in Interacting Systems," by C. R. Hardy, D. W. Miller, and B. K. Hajek, Proceedings of the Eighth Power Plant Dynamics, Control \&: Testing Symposium, Knoxville, Tennessee, May, 1992.

6. "Issues Involved in a Knowledge-Based A-pproach to Procedure Synthesis," by B. K. Hajek, L. F. Khartabil, and D. W. Miller. Transactions of the ANS Winter Meeting, Chicago, IL, November, 1992.

7. "Structured Residual Technique for Malfunction Isolation in Interacting Systems," by C. R. Hardy, D. W. Miller, B. K. Hajek. Transactions of the ANS Winter Meeting, Chicago, IL, November, 1992.

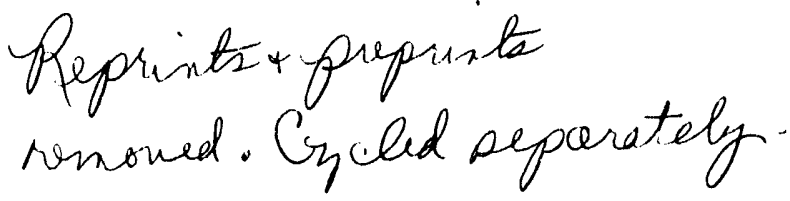


DATE

FILMED

$5 / 28 / 93$ 
